José Florencio F. Lapeña, Jr., MA, MD

Department of Otorhinolaryngology

College of Medicine, University of the Philippines Manila

Department of Otorhinolaryngology

Head and Neck Surgery

East Avenue Medical Center, Diliman, Quezon City
Correspondence: Prof. Dr. José Florencio F. Lapeña, Jr.

Department of Otorhinolaryngology

Ward 10, Philippine General Hospital

University of the Philippines Manila

Taft Ave., Ermita, Manila 1000

Philippines

Phone (632) 5264360

Telefax (632) 5244455

Email lapenajf@upm.edu.ph

Reprints will not be available from the author.

The author declared that this represents original material that is not being considered for publication or has not been published or accepted for publication elsewhere, in full or in part, in print or electronic media; that the manuscript has been read and approved by the author, that the requirements for authorship have been met by the author, and that the author believes that the manuscript represents honest work.

Disclosures: The author has no relevant financial or other (including personal) relationships, intellectual passion, political or religious beliefs, and institutional affiliations that might lead to a conflict of interest.

\section{Supporting Scholarly Writing Skills and Standards: Promotion and Priority}

\author{
"I'm deep inside a funny mood again, \\ like to brood again, if I could again \\ I feel like walking on a cloud again, \\ think aloud again, write and then..."1
}

The "Kuala Lumpur Declaration on Promotion of Scholarly Writing Skills and Standards in the Asia Pacific Region" was launched at the 2012 Convention of the Asia Pacific Association of Medical Journal Editors (APAME) held in Kuala Lumpur, Malaysia from 31 August to 3 September 2012. ${ }^{2}$ Considering the importance of "scholarly, scientific and technical health information" as an "invaluable resource" for "universal health promotion and policy development;" the necessity that this health information be "reliable, comprehensible and available" to the region and the world; the reality that the Asia Pacific region represents over half of the world population that both "generate(s) and need(s) an enormous amount of health information;" and that the Asia Pacific Association of Medical Journal Editors (APAME) "is an important catalyst for the promotion of scholarly writing skills and standards" that will "increase the reliability, comprehensibility and availability" of such vital health information; participants confirmed their commitment to "promoting scholarly writing skills and standards;" to the "continuing education of researchers, authors, reviewers and editors;" and to "collaboration with academic societies, universities, government and non-government organizations" in order to "ensure greater access to publication;" "empower them to write, review and edit;" and "promote research and publication" thereby "elevating loco-regional research and publishing to the global arena;" "promoting health and well-being in the region and the world;" and the "betterment of health and societal development in the region and globally."2

The promotion of scholarly writing skills and standards presupposes giving them preference, precedence or priority (1: the quality or state of being prior; 2 : precedence 3 : superiority in rank, position, or privilege; 4: a preferential rating; especially: one that allocates rights to goods and services usually in limited supply; 5: something given or meriting attention before competing alternatives). ${ }^{3}$ Without prioritization, promotion is mere lip service. Promotion (the act of furthering the growth or development of something; especially: the furtherance of the acceptance and sale of merchandise through advertising, publicity, or discounting ${ }^{4}$ in publishing entails concrete and sustained measures to ensure the growth and development of individual and collective researchers, authors, reviewers and editors, as well as librarians and ultimately, our readers. 
The Introductory Medical Writing Skills Workshop co-hosted by the Philippine Society of Otolaryngology Head and Neck Surgery on November 17, 2012 embodies "our commitment to the continuing education of researchers, authors, reviewers and editors, to empower them to write, review and edit scholarly manuscripts for publication and dissemination, thereby promoting health and well-being in the region and the world."2 This workshop begins the formal introduction of Fellows, Diplomates and Resident Physicians to "scholarly writing skills and standards, in order to set the example for our peers, authors, reviewers, editors and librarians." ${ }^{2}$

We are conducting or have conducted similar workshops in Manila, Davao, Cebu, Baguio and Iloilo as well as in Singapore, Malaysia, Brunei Darussalam, India, Vietnam and Cambodia. Ultimately, this workshop will help the Philippine Journal of Otolaryngology Head and Neck Surgery attain "increasing scholarly quality worthy of continued production and dissemination."
I was especially gratified to recently learn from a colleague that a 2009 article published in our journal had generated an inquiry from a potential patient in Australia, who was in search of a therapeutic solution for his problem. It is this same visibility that generates submissions from various countries, which to date includes Malaysia, India, Brunei Darussalam, Japan, New Zealand, Turkey and the United States of America. As we continue to grow and nurture our international pool of authors, reviewers and editors, may we likewise harvest more and more local talent for the various roles that make up our journal.

I am very happy to announce that the Philippine Journal of Otolaryngology Head and Neck Surgery is now also indexed on the Asia Pacific Medical Journal Articles Central Archives (APAMED Central) available at $h t t p: / / a p a m e d c e n t r a l . o r g /$ a digital archive and reference linking platform of journals published in Member States of the WHO Western Pacific Region and Southeast Asian Region, supported by the World Health Organization and powered by KoreaMed Synapse. This additional archive ensures our increasing presence to the rest of the world, promoting greater visibility of our published research.

2. Asia Pacific Association of Medical Journal Editors (APAME) "Kuala Lumpur Declaration on Promotion of Scholarly Writing Skills and Standards in the Asia Pacific Region" 2012. Available at http://www2.wpro.who.int/NR/rdonlyres/18B2D878-AA4B-4933-B008-86A48DCF7B8A/0/ APAME2012KLDeclaration.pdf Cited on 31 October 2012; co-published as a Special Announcement in the Philipp J Otolaryngol Head Neck Surg 2012 Jul-Dec;27(2):5.

3. Priority. (2012) In Merriam-Webster Online Dictionary. Retrieved October 31, 2012, from http:// www.merriam-webster.com/dictionary/priority

4. Publication. (2012) In Merriam-Webster Online Dictionary. Retrieved October 31, 2012, from http://www.merriam-webster.com/dictionary/promotion
} 